\title{
Human platelet reactivity during stressful diagnostic procedures
}

\author{
J. L. GORDON, D. E. BOWYER, D. W. EVANS, AND M. J. MITCHINSON \\ From the Department of Pathology, Cambridge University, and Papworth and Addenbrooke's \\ Hospitals, Cambridge
}

SYNOPSIS Conscious subjects undergoing cardiac catheterization and other diagnostic procedures $\stackrel{\circ}{\sim}$ showed a rise in platelet-aggregation response to adenosine diphosphate (ADP) one hour before 8 and during the procedure. The responses returned towards normal one hour afterwards. The $\infty$ response to glass beads was decreased one hour before the procedure, but was unchanged in subsequent $\stackrel{\circ}{\rightrightarrows}$ samples. Plasma-free fatty acid (FFA) levels were increased during the procedure, and one hour afterwards, but had returned to normal by the following day. Platelet counts were slightly reduced on the day after the procedure. It is suggested that catecholamines released due to emotional stress may be responsible for the increased platelet responses to ADP and that this could influence the development of thrombosis and atherosclerosis.

Catecholamines cause an increase in plasma concentrations of FFA in man (Wenke, 1966). It has been suggested that catecholamine-mediated increases in plasma FFA levels during periods of emotional stress may be important in thrombogenesis (Hoak, Poole, and Robinson, 1963; Taggart and Carruthers, 1971).

The addition of FFA to platelet-rich plasma causes platelet aggregation (Hoak, Spector, Fry, and Warner, 1970), and the intravenous infusion of fatty acids in dogs produces platelet thrombi (Conner, Hoak, and Warner, 1966). Also, injection of ACTH or anterior pituitary extract in rabbits results in an increase in plasma FFA and the formation of intravascular platelet aggregates (Hoak et al, 1963).

If stress does enhance the formation of platelet thrombi, then the plasma FFA levels may or may not be implicated, because catecholamines themselves can induce platelet aggregation in vitro (Mitchell and Sharp, 1964), and can also potentiate aggregation induced by ADP (Ardlie, Glew, and Schwartz, 1966).

There are few data on platelet reactivity in conscious subjects during emotional stress (Harrison, Emmons, and Mitchell, 1967). Therefore, the present study was undertaken in order to monitor platelet aggregation responses and plasma FFA concentra-

Received for publication 22 August 1973. tions in conscious patients undergoing potential stressful diagnostic procedures.

\section{Materials and Methods}

PATIENTS

Twelve adult patients were studied before and during potentially stressful diagnostic procedures without general anaesthetic (table). The patients' informed consent was obtained for withdrawal of blood samples; apart from this the diagnostic procedures were performed routinely. The procedures to be followed were outlined to all patients in advance. The patients were receiving a variety of drugs, but no adrenergic blocking agents were included.

BLOOD SAMPLES

All samples were taken by antecubital venepuncture, into $1 / 10 \mathrm{v} / \mathrm{v}$ acid-citrate-dextrose (Aster and Jandl, O 1964) and only samples obtained without any diffi- $N$ culty were accepted. In most cases, the patient had $N$ been resting in bed for at least 30 minutes before $\sigma$ every sample taken on the ward, and had eaten only a light breakfast (tea and toast) about two hours before the first sample.

On the day before the procedure, two samples were taken about one hour apart. On the next day, before the patient left the ward, a sample was taken approxi- $\overrightarrow{\mathbb{D}}$ mately one hour before the start of the diagnostic 


\begin{tabular}{|c|c|c|c|c|}
\hline $\begin{array}{l}\text { Patient } \\
\text { No. }\end{array}$ & Age/Sex & $\begin{array}{l}\text { Principal Clinical } \\
\text { Diagnosis }\end{array}$ & $\begin{array}{l}\text { Drug Therapy at Time of } \\
\text { Investigation }\end{array}$ & Investigation \\
\hline 1 & $58 / \mathbf{M}$ & $\begin{array}{l}\text { Benign prostatic } \\
\text { hyperplasia }\end{array}$ & Propantheline & $\begin{array}{l}\text { Intravenous } \\
\text { pyelogram }\end{array}$ \\
\hline 2 & $49 / \mathrm{M}$ & Chronic bronchitis & Prenylamine & $\begin{array}{l}\text { Right heart } \\
\text { catheterization }\end{array}$ \\
\hline 3 & $17 / \mathbf{M}$ & Cardiomyopathy & & $\begin{array}{l}\text { Left heart } \\
\text { catheterization and } \\
\text { selective coronary } \\
\text { arteriography }\end{array}$ \\
\hline 4 & $49 / M$ & Aortic incompetence & & $\begin{array}{l}\text { Right and left heart } \\
\text { catheterization, } \\
\text { aortography, and } \\
\text { selective coronary } \\
\text { arteriography }\end{array}$ \\
\hline 5 & $58 / \mathrm{M}$ & Carcinoma bronchus & Ferrous sulphate & Lung biopsy \\
\hline 6 & $54 / M$ & Cardiomyopathy & $\begin{array}{l}\text { Ethacrynic acid } \\
\text { Slow K }\end{array}$ & $\begin{array}{l}\text { Left heart } \\
\text { catheterization }\end{array}$ \\
\hline 7 & $31 / \mathbf{M}$ & Hepatoma & & $\begin{array}{l}\text { Hepatic } \\
\text { arteriography }\end{array}$ \\
\hline 8 & $47 / M$ & $\begin{array}{l}\text { Atrial septal defect, } \\
\text { systemic hypertension, } \\
\text { and coronary } \\
\text { artery disease }\end{array}$ & $\begin{array}{l}\text { Guanethidine, frusemide, } \\
\text { Slow K, digoxin }\end{array}$ & $\begin{array}{l}\text { Left heart } \\
\text { catheterization and } \\
\text { selective coronary } \\
\text { arteriography }\end{array}$ \\
\hline 9 & $49 / \mathrm{M}$ & $\begin{array}{l}\text { Myocardial } \\
\text { infarction with left } \\
\text { ventricular aneurysm }\end{array}$ & $\begin{array}{l}\text { Digoxin, frusemide, } \\
\text { Slow K }\end{array}$ & $\begin{array}{l}\text { Right and left heart } \\
\text { catheterization and } \\
\text { selective coronary } \\
\text { arteriography }\end{array}$ \\
\hline 10 & $44 / F$ & $\begin{array}{l}\text { Coronary artery } \\
\text { disease and } \\
\text { hyperlipidaemia }\end{array}$ & Doxepin, pentazocine & $\begin{array}{l}\text { Left heart } \\
\text { catheterization and } \\
\text { selective coronary } \\
\text { arteriography }\end{array}$ \\
\hline 11 & $46 / M$ & Mitral stenosis & $\begin{array}{l}\text { Digoxin, frusemide, } \\
\text { Slow } \mathbf{K}\end{array}$ & $\begin{array}{l}\text { Right heart } \\
\text { catheterization }\end{array}$ \\
\hline 12 & $56 / M$ & Mitral incompetence & $\begin{array}{l}\text { Warfarin, frusemide, } \\
\text { Slow K, lanatoside C }\end{array}$ & $\begin{array}{l}\text { Right and left } \\
\text { heart catheterization }\end{array}$ \\
\hline
\end{tabular}

Table Brief clinical data of patients

${ }^{1}$ Excluding premedication, which varied (diazepam, phenobarbitone, or omnopon and scopolamine; isosorbide dinitrate where coronary arteriography scheduled and antibiotic prophylaxis in all cardiac catheterization cases).

Patient no 1 had no premedication.

procedure ( $-1 \mathrm{hr}$ sample); one or two samples were taken during the procedure (depending on its duration) and a further sample about one hour after the end of the procedure $(+1 \mathrm{hr}$ sample). If two samples were taken during the procedure, the results were averaged. In the first three patients studied, samples were withdrawn during the procedure from an arterial catheter simultaneously with the venous samples. No significant differences in platelet reactivity were found between arterial and venous samples and arterial samples were subsequently abandoned. A final sample was taken on the day after the procedure $(+24 \mathrm{hr}$ sample) under the same conditions as for the $-24 \mathrm{hr}$ sample.

\section{Platelet AGgRegation tests}

Aggregation responses to ADP and glass beads were measured in whole blood by the semimicro method of Gordon and Gresham (1972). In brief, the method involved addition of the aggregating agents to $0.5 \mathrm{ml}$ aliquots of blood in small polystyrene tubes. These were mixed for $60 \mathrm{sec}$ at $37^{\circ} \mathrm{C}$ and an equal volume of Eagle's medium was added to promote erythrocyte sedimentation. After $15 \mathrm{~min}$ unaggregated platelets in the supernatants were counted electronically, and aggregation was calculated as the percentage reduction in count compared with an unmixed control. All determinations were performed in duplicate, and the results averaged. A preliminary platelet 
aggregation test was performed on the first sample and, on the basis of the results, concentrations of ADP and glass beads were chosen for use on all subsequent samples. Previous results had shown that a sigmoid curve was obtained when aggregation was plotted against $\log _{10}$ concentration of aggregating agent (Gordon and Gresham, 1972). To facilitate detection of any changes in aggregation response, the initial responses should lie on the central, linear part of the curve. Therefore, aggregating stimuli were chosen to give responses in control samples of around 30 to $50 \%$ aggregation. In practice the concentrations selected were either $2 \mu \mathrm{M}$ or $4 \mu \mathrm{M}$ ADP and $200 \mathrm{mg}$ or $400 \mathrm{mg}$ beads. The results from the second sample $(-24 \mathrm{hr}$ sample) were taken as the control values for the patient.

\section{FREE FATTY ACID ESTIMATION}

For the first three patients studied individual free fatty acids were measured by gas-liquid chromatography (Bowyer, Leat, Howard, and Gresham, 1963), but since no single fatty acid showed a pattern of change which was not reflected in the total FFA level, this practice was discontinued. In all subsequent patients, total plasma FFA were estimated by a new AutoAnalyzer technique (D. E. Bowyer and J. S. Cridland, to be published). In summary, the method is as follows. Plasma samples $(0.2 \mathrm{ml})$ were added to a suspension of $1 \mathrm{~g}$ silica gel in $3 \mathrm{ml}$ water. Di-n-butyl ether $(3 \mathrm{ml})$ was then added, and the mixture was stirred vigorously for $30 \mathrm{sec}$, then centrifuged for $10 \mathrm{~min}$ at $1000 \mathrm{~g}$. The supernatant was assayed on an AutoAnalyzer by mixing with a copper reagent (M50 cupric acetate in 4:1 water: glycerol, containing also $2 \% \mathrm{w} / \mathrm{v}$ pyrrolidone) for six min, then separating the organic phase and reacting this with $0.2 \% \mathrm{w} / \mathrm{v} 1,5$ diphenylcarbazide in propan-2-ol, containing $0.5 \% \mathrm{w} / \mathrm{v}$ acetic acid. The colour which developed was measured at its maximum absorbence of $550 \mathrm{~nm}$.

\section{Results}

Platelet aggregation responses, plasma FFA levels, and platelet counts for all samples are presented as group mean values (fig 1 ). The $-24 \mathrm{hr}$ values have been compared with all subsequent values in turn, by paired $t$ test, and the levels of significance achieved are indicated.

Platelet aggregation induced by ADP was significantly $(P<0.001)$ increased in samples taken one $\mathrm{hr}$ before and during the diagnostic procedure but had returned towards the control value by one $\mathrm{hr}$ afterwards. The group mean aggregation response had not completely returned to the control level in the $+24 \mathrm{hr}$ sample but this was due to three subjects

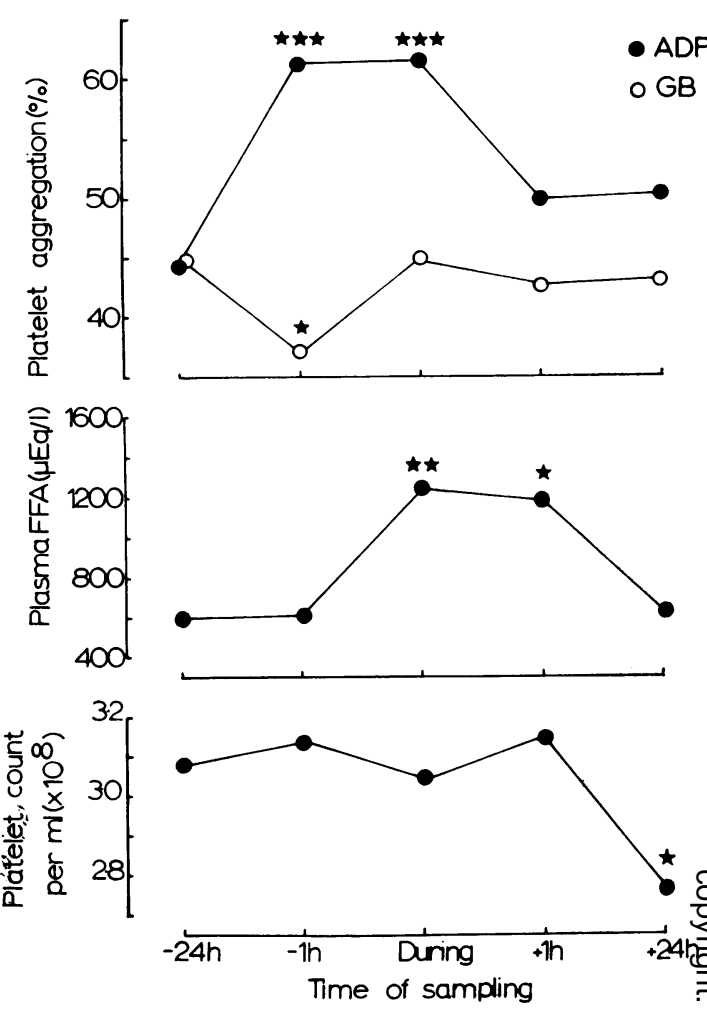

Fig 1 Platelet aggregation responses, plasma FFA levels, and platelet counts in patients undergoing diagnostic procedures. Each point represents the group mean value. The $-24 \mathrm{hr}$ values have been compared with all subsequent values in turn, and levels of significance are shown.

${ }^{*} \mathrm{P}<0.05 ; \quad{ }^{* *} \mathrm{P}<0.01 ; \quad * * * \mathrm{P}<0.001$

(patients nos. 2, 11, and 12) who showed a marked rise in their $+24 \mathrm{hr}$ sample. In each of the other nine subjects, the $+24 \mathrm{hr}$ value was within $3 \%$ of the $-24 \mathrm{hr}$ value.

Platelet aggregation induced by glass beads was reduced $(\mathrm{P}<0.05)$ one $\mathrm{hr}$ before the operation, but did not differ significantly from the control value in any subsequent samples.

The group mean plasma FFA level was not altered one $\mathrm{hr}$ before the operation, but was significantly $\mathrm{N}$ $(P<0.01)$ increased during the procedure and was still elevated $(\mathrm{P}<0.05)$ one $\mathrm{hr}$ afterwards. It had returned to the control value by the following day.

The group mean platelet count did not change in the samples taken on the day of the procedure, but $\stackrel{\Phi}{\rightarrow}$ was significantly $(\mathrm{P}<0.05)$ reduced on the following day.

The divergent changes in platelet aggregation induced by ADP and by glass beads, in the $-1 \mathrm{hr}$ 
samples, were most consistent: each occurred in 11 of the 12 subjects (fig 2 ). The same subject was not responsible for the one anomalous response recorded in each group.

There was no correlation between platelet reactivity and the FFA level in individual blood samples, nor between the magnitude of changes in aggregation responses and the subsequent rise in plasma FFA in individual subjects.

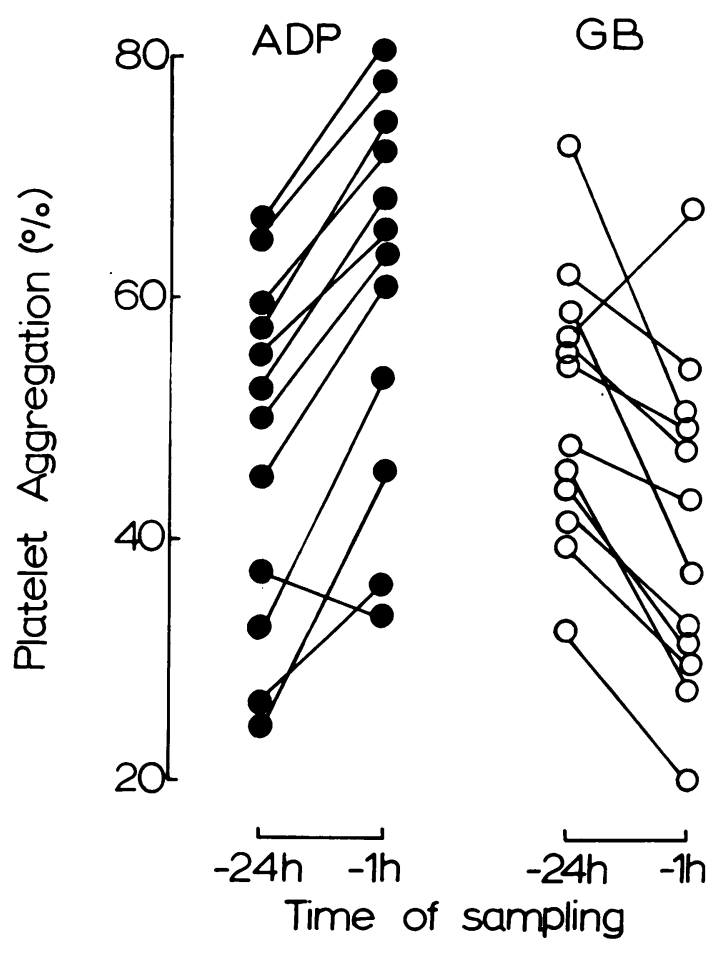

Fig 2 Platelet aggregation responses to $A D P$ and glass beads in subjects tested $24 \mathrm{hr}$ and one hr before diagnostic procedures.

\section{Discussion}

Studies of reactivity of platelets taken from hospital patients entail a number of disadvantages. One of these is that the observed changes in reactivity are possibly the result of the interaction of a large number of variables in vivo. Therefore the heterogeneity of the subjects, amply demonstrated in the table, could make results difficult to interpret. Paradoxically, however, this might be regarded as an advantage when, as here, relatively constant changes are seen in such a heterogeneous group.
The results obtained in this study suggest that the platelets of these patients became more reactive to adenosine diphosphate before and during a stressful diagnostic procedure. This increased reactivity appeared to precede changes in the plasma concentrations of free fatty acids, and to be independent of them in subsequent samples. Similar lack of correlation was found by Bridges and his colleagues (Bridges, Dalby, Hadden, Johnston, and Weaver, 1967) in human volunteers after administration of growth hormone or nicotinic acid. Jacobsson (1969) found increased platelet reactivity in patients during arterial catheterization and concluded that this was due to the presence of the catheter. In the present study, however, the response to ADP was as great in the $-1 \mathrm{hr}$ sample as during the procedure, and similar patterns of response were seen whether or not intravascular catheterization was undertaken. The changes were therefore not primarily due to catheterization, nor to introduction of heparin, nor to any of the other manipulations of the diagnostic procedure.

The drug regime and premedication given varied from patient to patient, and in one case there was no premedication at all; it therefore seems unlikely that the changes seen were drug-dependent. The observed changes also appear to be independent of the diagnostic procedure undergone, and of the presence or absence of ischaemic heart disease.

At first sight, the changes in ADP response in this study appear to conflict with the results of O'Brien, Etherington, and Jamieson (1971) who found a decreased aggregation response to ADP during surgery. However, patients in that study were undergoing major operations under general anaesthesia. The release of ADP from damaged tissue in such circumstances is probably considerable, and it was suggested that this exposure of the circulating platelets to ADP rendered them temporarily refractory to the ADP stimulus in subsequent tests in vitro (O'Brien et al, 1971). In the present study, however, tissue trauma was probably minimal during the procedures, and totally absent one hour previously.

O'Brien, Etherington, Jamieson, and Klaber (1972) later reported a decreased aggregation response to ADP and an increased response to glass beads in samples taken immediately after a major operation, compared with preoperative levels, but they did not state how long before the operation the preoperative samples were taken. In the present study, the response to glass beads during and after the procedures was increased compared with the value one hour before, but not when compared with the value 24 hours before.

O'Brien and his colleagues (1972) found the glass bead response difficult to reconcile with their other results, and commented on the dangers of extra- 
polating from one set of observations to another, if different platelet tests were used. All our tests were performed by direct platelet counting in whole blood, which might explain differences between our results and those obtained by photometric measurements in platelet-rich plasma. We have no explanation for the disparate patterns of response to ADP and to glass beads, but such observations support the concept that there are fundamental differences between platelet responses to added ADP and to glass contact (O'Brien, 1972). The physiological relevance of glass-bead tests of platelet function is often debated, and because ADP is known to play an essential role in platelet aggregation both in vitro and in vivo (Begent and Born, 1970), we believe that tests using ADP may be more representative of the situation in vivo.

Blood catecholamine levels rise during emotional stress (Taggart and Carruthers, 1971). Catecholamines can induce platelet aggregation in vitro (Mitchell and Sharp, 1964) and in vivo (Haft, Kranz, Albert, and Fani, 1972) but prior exposure to catecholamines does not make platelets refractory to subsequent stimulation by ADP (O'Brien, 1966). In fact, the presence of catecholamines stabilizes ADP-induced aggregation (Ardlie et al, 1966).

Ramsay (1972) found that $73 \%$ of patients awaiting surgery were anxious or fearful; we suggest that, in the subjects of the present study, catecholamines released due to emotional stress before and during the procedures could have been responsible for increasing platelet reactivity to ADP. Catecholaminemediated changes in platelet responsiveness to ADP might thus provide an additional pathway by which stress could influence the origin of thrombosis and atherosclerosis. The rise observed in plasma FFA in this study, probably also catecholamine-mediated, was unlikely to have been responsible for the changes in platelet reactivity, for the reasons stated.

Further investigations are necessary to elucidate these findings. Subjects undergoing other forms of stress should be investigated, and attempts made to reproduce the phenomenon in experimental animals by injection of catecholamines. This work is in progress.

This study was supported in part by a clinical research grant from the United Cambridge Hospitals. We thank Drs H. Fleming and R. J. Wilson, Mr J. F. R. Withycombe, and Professor R. Y. Calne for permission to study their patients. Miss Rosemary Carter provided valuable technical assistance.

\section{References}

Ardlie, N. G., Glew, G., and Schwartz, C. J. (1966). Influence of catecholamines on nucleotide-induced platelet aggregation. Nature (Lond.), 212, 415-417.

Aster, R. H., and Jandl, J. H. (1964). Platelet sequestration in man. ? I. Methods. J. clin. Invest., 43, 843-855.

Begent, N., and Born, G. V. R. (1970). Growth rate in vivo of platelet $\vec{\omega}$ thrombi, produced by iontophoresis of ADP, as a function of $\mathrm{S}$ mean blood flow velocity. Nature (Lond.), 227, 926-930.

Bowyer, D. E., Leat, W. M. F., Howard, A. N., and Gresham, G. A. (1963). The determination of the fatty acid composition of $N$ serum lipids separated by thin-layer chromatography; and a $?$ comparison with column chromatography. Biochem. biophys. $\vec{N}$ Acta. (Amst.), 70, 423-431.

Bridges, J. M., Dalby, A. M., Hadden, D. R., Johnston, H. A., and of Weaver, J. A. (1967). The effect of in vivo alteration of free $\infty$ fatty acids on platelet stickiness. J. Atheroscler. Res., 7, 695-699. 응

Connor, W. E., Hoak, J. C., and Warner, E. D. (1966). The role of lipids in thrombosis. Thromb. Diathes. haemorr. (Stuttg.), Suppl., 21, 193-208.

Gordon, J. L., and Gresham, G. A. (1972). The measurement of platelet aggregation in small blood samples. Atherosclerosis, $15,383-386$.

Haft, J. I., Kranz, P. D., Albert, F. J., and Fani, K. (1972). Intravascular platelet aggregation in the heart induced by norepinephrine: microscopic studies. Circulation, 46, 698-708.

Harrison, M. J. G., Emmons, P. R., and Mitchell, J. R. A. (1967 The variability of human platelet aggregation. J. Atheroscle $\omega$ Res., 7, 197-205.

Hoak, J. C., Poole, J. C. F., and Robinson, D. S. (1963). Thrombo associated with mobilization of fatty acids. Amer J. Path., 43 987.998.

Hoak, J. C., Spector, A. A., Fry, G. L., and Warner, E. D. (1970). Effect of free fatty acids on ADP-induced platelet aggregation. Nature (Lond.), 228, 1330-1332.

Jacobsson, B. (1969). Effect of vascular catheterisation on blood coagulation. Europ. surg. Res., 1, 290-298.

Mitchell, J. R. A., and Sharp, A. A. (1964). Platelet clumping in vitro. Brit. J. Haemat., 10, 78-93.

O'Brien, J. R. (1966). Changes in platelet membranes possibly associated with platelet stickiness. Nature (Lond.), 212, 1057-1058.

O'Brien, J. R. (1972). Platelet adhesion and aggregation. Brit.med.J., 3,350 .

O’Brien, J. R., Etherington, M., and Jamieson, S. (1971). Refractory state of platelet aggregation with major operations. Lancet, 2, 741-743.

O'Brien, J. R., Etherington, M., Jamieson, S., and Klaber, M. R. (1972). Platelet function in venous thrombosis and low dosage heparin. Lancet, 1, 1302-1305.

Ramsay, M. A.E. (1972). A survey of pre-operative fear. Anaesthesia, 윽 $27,396-402$.

Taggart, P., and Carruthers, M. (1971). Endogenous hyperlipidaemia $D$ induced by emotional stress of racing driving. Lancet, 1, 36fl-366.

Wenke, M. (1966). Effects of catecholamines on lipid metabolism Advanc. Lipid Res., 4, 69-105. 